\title{
Comparative study of post placental cut insertion following vaginal and caesarean delivery
}

\author{
Jasmine Lall*, Oby Nagar
}

Department of Obstetrics and Gynecology, SMS Medical College, Jaipur, Rajasthan, India

Received: 05 February 2017

Accepted: 09 February 2017

\author{
*Correspondence: \\ Dr. Jasmine Lall, \\ E-mail: drjasminelall24@gmail.com
}

Copyright: (C) the author(s), publisher and licensee Medip Academy. This is an open-access article distributed under the terms of the Creative Commons Attribution Non-Commercial License, which permits unrestricted non-commercial use, distribution, and reproduction in any medium, provided the original work is properly cited.

\section{ABSTRACT}

Background: The IUCD is a safe and effective contraceptive option for postpartum women who wish to either space or limit subsequent births.

Methods: In a hospital based prospective observational, study we compared outcome of post placental IUCD in vaginal and caesarean delivery groups.

Results: We found that expulsion rate is significantly higher in vaginal group (10\%) as compared to caesarean delivery (2\%) group at 3 months of follow up. Excessive bleeding is mostly commonly found complication (18\% in both groups at 6weeks of follow up).

Conclusions: Women who receive PPIUCD show a high level of satisfaction with this choice of contraception, and the rates of expulsion were low enough such that the benefits of contraceptive protection outweigh the potential inconvenience of needing to return for care for that subset of women.

Keywords: Bleeding, Expulsion, PPIUCD

\section{INTRODUCTION}

India is the second most populated country in the world after China with an estimated total population of 1.26 billion. India's maternal mortality ratio stays at an alarming figure of 254/100000 live births, which cause $1,17,000$ women to die from pregnancy and child birth complications every year. This contributes to $20 \%$ of global maternal deaths. ${ }^{1}$

In India, $65 \%$ of women in the first year postpartum have an unmet need for family planning. ${ }^{2}$ Intrauterine devices (IUDs) have been used by women in India for decades for spacing pregnancy. Copper IUDs are the most commonly used type of IUD and the $\mathrm{Cu} \mathrm{T} 380 \mathrm{~A}$ has been found to be most effective IUD available in govt. sector free of charge. ${ }^{3}$

Appropriate times for IUCD insertion in the postpartum periods include the postplacental IUCD insertion, the immediate postpartum IUCD insertion and the transcaesarean IUCD insertion. Taking advantage of the immediate postpartum period for counselling on family planning, IUCD is a good option as a contraceptive method. The increased institutional deliveries provide the opportunity to provide women easy access to immediate PPIUCD services. The National Family Health Survey (2005-2006) reported that $61 \%$ of births were spaced less than $3 y r s$ in India. Unmet need is greater in 1st year postpartum. Only $3-5 \%$ of post-partum women wants another child within two years. ${ }^{4}$

To address the unmet need during the post-partum period the Ministry of Health and Family Welfare, Government of India developed a national strategy to expand PostPartum Intrauterine Device (PPIUD) services among public sector facilities. Since, not much work has been done in assessing the complications and side effects of PPIUCD in caesarean and vaginal deliveries, we decided to undertake this study. 


\section{METHODS}

The present study is hospital based prospective study carried out at Department of Obstetrics \& Gynaecology, S.M.S. Medical College \& attached group of Hospitals, Jaipur from March 2015 onwards. Present study was conducted on the patients undergoing deliveries at Mahila Chikitsalaya, SMS Medical College, Jaipur for a period of one year (March 2015 to Feb 2016).

Sample size is calculated at $80 \%$ study power and alpha error of .05 assuming $75 \%$ continuation rate till 6 months of PPIUCD in normal vaginal delivery cases and $90.24 \%$ in caesarean section cases as found in the study of Sharma A et al. \{Int J Res Med Sci. 2015 Jan;3(1)183$187\} .94$ Cases in each group are required with continuity correction which are further enhanced to 100 cases in each group considering $15 \%$ dropout rate as per reference article.

\section{Selection of patients}

\section{Inclusion criteria}

- Women in immediate post placental period (within 10 minutes of placental expulsion) in vaginal and caesarean delivery.

- All women who give consent to participate in the study.

\section{Exclusion criteria}

- $\quad$ PPH

- $\quad$ PROM > 18 hours

- Congenital uterine anomaly

- History of any previous ectopic pregnancy

- Distorted uterine cavity

- Patients consenting for sterilization

- Chorioamnionitis

\section{Plan of action}

Informed consent of all the eligible candidates will be taken. Inclusion and exclusion criteria will be taken into consideration.

\section{Recruitment plan}

The study participants will be recruited from Inpatients of the Department of Obstetrics and Gynaecology. All patients will be subjected to detailed history, clinical examination and relevant investigations.

\section{Procedure details}

All pregnant women who are attending our antenatal clinic or admitted in the labor ward will be counseled for different postpartum family planning methods. Those women who chose PPIUD will be informed regarding advantages, limitations, effectiveness and side effects related to IUD. Every woman will be screened for clinical situations as per WHO medical eligibility criteria in the antenatal period, as well as immediately prior to insertion after delivery. After obtaining Informed consent in all subjects. The PPIUD (CuT-380A) will be placed within 10 minutes following delivery of the placenta using Kelly's placental forceps. Subjects will be followed up at 6 weeks postpartum and then at 3 months. During the follow up visit they will be subjected to detailed history and Per Speculum examination. Cases in which threads are not visible USG pelvis will be done to confirm the presence of IUCD in the uterus.

\section{Statistical analysis}

Statistical analysis: Descriptive statistics will be used to describe demographic variables and clinical characteristics. Continuous variable will be summarized as mean and SD whereas Nominal/Categorical variables as proportion unpaired $\mathrm{T}$ test will be used (\%) for comparison of continuous variable while Chi square test will be used for Nominal/Categorical variables. $\mathrm{P}<0.05$ will be taken as significant Med Calc 14.0.0 software will be used for statistical calculation.

\section{RESULTS}

As far as vital statistics are concerned most of the subject in Vaginal delivery group (88\%) and LSCS group (89\%) belonged to $20-30$ years age group.

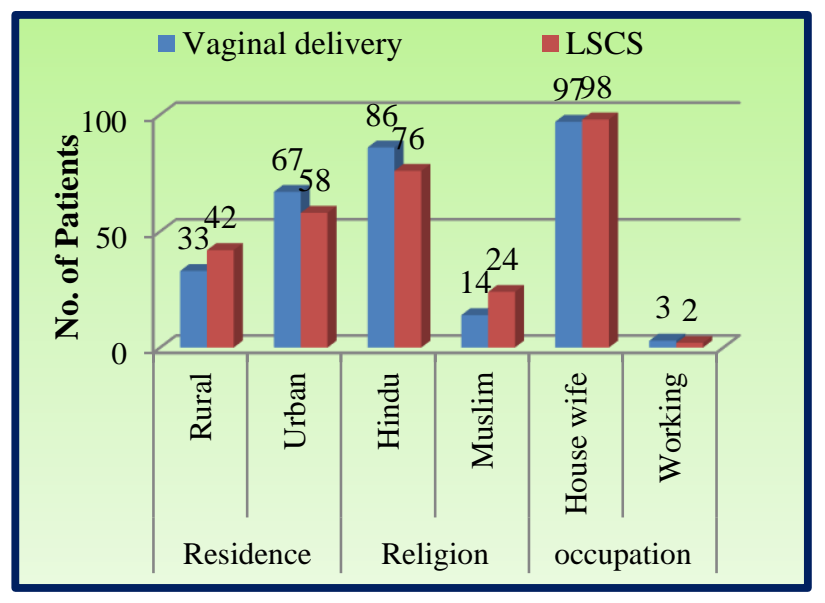

Figure 1: Sociodemographic profile of study subjects.

Application of Chi square test revealed that the two groups did not differ significantly in their age composition. Socio demographic profile of our patients showed that $67 \%$ of the subjects in vaginal Delivery group and $58 \%$ of Subject in LSCS group belonged to urban area and this difference was not found to be statistically significant $(\mathrm{p}=0.243$ ) (Figure 1$)$. Contrary to common believe, only $27 \%$ of the study subjects $(24 \%$ of Vaginal Delivery group and $30 \%$ of the LSCS group) had parity 3 or more and as much as one third of subjects had 
parity one which indicates early acceptability of long term contraceptive in our study. Chi square test showed that the two group did not differ significantly in relation to their parity $(\mathrm{p}=0.113)$. Pelvic pain and excessive bleeding are two most common complications found in our study. We found that $57.5 \%$ of the subjects had no complain at 6 week follow up (52\% in vaginal delivery group and $63 \%$ in LSCS group). At 3 months follow up $55 \%$ subjects in vaginal delivery group and $53 \%$ in LSCS group did not have any complain.

Table 1: Comparison of study groups on basis of complain of pelvic pain.

\begin{tabular}{|c|c|c|c|c|c|c|c|}
\hline \multirow{2}{*}{ Follow up time } & \multicolumn{2}{|c|}{ Vaginal Delivery } & \multicolumn{2}{|c|}{ LSCS } & \multicolumn{2}{|c|}{$\begin{array}{l}\text { Total no. of subjects } \\
\text { with pelvic pain }\end{array}$} & \multirow{2}{*}{$\begin{array}{l}\text { P value* } \\
\text { (significance) }\end{array}$} \\
\hline & $\mathbf{N}$ & $\%$ & $\mathbf{N}$ & $\%$ & $\mathbf{N}$ & $\%$ & \\
\hline 6 week & 16 & 16 & 20 & 20 & 36 & 18 & $0.581(\mathrm{NS})$ \\
\hline 3 months & 10 & 10 & 11 & 11 & 21 & 10.5 & $1.000(\mathrm{NS})$ \\
\hline
\end{tabular}

* P value calculated using Chi square test.

Table 2: Comparison of study groups on basis of complain of excessive vaginal bleeding.

\begin{tabular}{|c|c|c|c|c|c|c|c|}
\hline \multirow{2}{*}{$\begin{array}{l}\text { Follow up } \\
\text { time }\end{array}$} & \multicolumn{2}{|c|}{ Vaginal Delivery } & \multicolumn{2}{|c|}{ LSCS } & \multicolumn{2}{|c|}{$\begin{array}{l}\text { Total no. of subjects with } \\
\text { excessive vaginal bleeding }\end{array}$} & \multirow{2}{*}{$\begin{array}{l}\text { P value* } \\
\text { (significance) }\end{array}$} \\
\hline & $\mathbf{N}$ & $\%$ & $\mathbf{N}$ & $\%$ & $\mathbf{N}$ & $\%$ & \\
\hline 6 week & 21 & 21 & 15 & 15 & 36 & 18 & 0.357 (NS) \\
\hline 3 months & 19 & 19 & 8 & 8 & 27 & 13.5 & $0.039(\mathrm{~S})$ \\
\hline
\end{tabular}

* P value calculated using Chi square test.

The two groups did not differ significantly in relation to absence of complaint at 6 weeks and 3 months follow up. About $16 \%$ of subjects in vaginal delivery group and $20 \%$ of patients in LSCS group developed Pelvic pain at 6 week follow up and at 3 months follow up only 10\% and $11 \%$ subjects in vaginal delivery group and LSCS group respectively had Pelvic pain. Application of Chi square test revealed that the two groups did not differ significantly in occurrence of Pelvic pain at 6 week and 3 months follow up (Table 1). In present study, we found that $18 \%$ of subjects had complains of excessive vaginal bleeding at 6 weeks follow up. At 3 months follow up more patients in vaginal delivery group (19\%) had complain of excessive vaginal bleeding as compared to LSCS group (8\%) and this difference was found to be statistically significant $(\mathrm{p}=0.039)$. Overall $13.5 \%$ of subjects had excessive bleeding at 3 months follow up. (Table 2). Pelvic inflammatory disease is another point of concern in IUCD users. In our study, foul smelling discharge was seen in only $5 \%$ of subjects in vaginal delivery group and none of the subjects in LSCS group, However, this difference was not found to be statistically significant $(\mathrm{P}=0.07)$. Overall prevalence of Foul smelling discharge was low i.e. $2 \%$ and $2.5 \%$ at 6 week and 3 months follow up respectively. Thread visibility is a important yard stick for knowing the retention of IUCD but this parameter can be misleading in caesarean cases due to process of involution, we found that at 6 weeks follow up thread visibility in vaginal delivery group was significantly higher $(96 \%)$ as compared to LSCS group (60\%); P value $<0.001$, overall the thread visibility was not significantly different at among the two group at 3 month follow up $(\mathrm{p}=0.075)$.

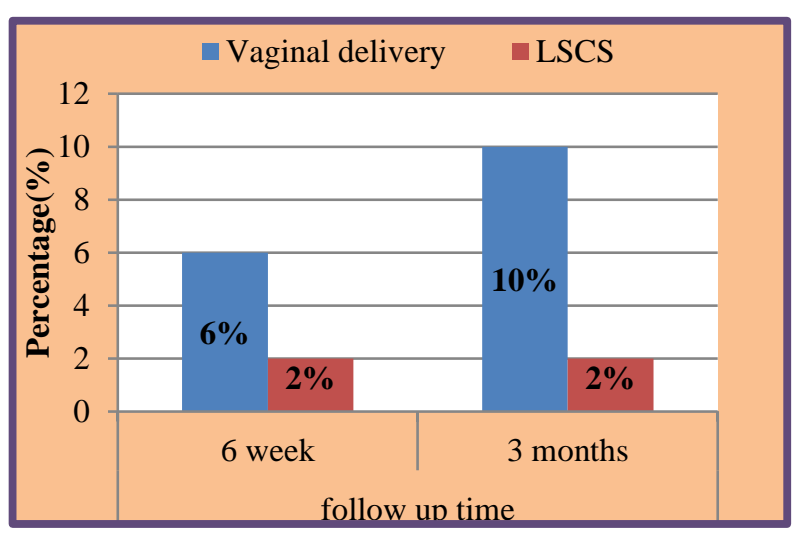

Figure 2: Comparison of expulsion rate at 6 weeks and 3 months follow up.

Expulsion of IUCD is very important and well known complication of IUCD. In present study, it was found that at 3 months follow up expulsion rate in vaginal delivery group was significantly higher $(10 \%)$ as compared to LSCS group (2\%); P value $=0.037$. Overall the expulsion rate was $6 \%$ at 3 months. (figure 2). In this present study, over all continuation rate for PPIUCD was good $(84.5 \%)$ at 3 months follow up. Continuation rate was significantly higher in LSCS group (91\%) as compared to vaginal delivery group $(78 \%) ; \mathrm{p}=0.019$.

\section{DISCUSSION}

This study was carried out to determine acceptability, uptake and outcome of PPIUCD placement together with 
assessing the success that is the continuation rate at the end of the puerperium in a cohort of mothers who underwent normal and caesarean delivery and required a long term reversible method of contraception. Our study of PPIUCD use in India showed that most women were satisfied with their choice of immediate insertion of an IUCD and that the rates of problems and complications were relatively low. Though post-partum IUCD insertion immediately after delivery is an upcoming topic, its efficacy and safety is to be determined. Various studies were carried out to determine its efficacy, safety outcome using different techniques of insertion, but data on postpartum IUCD insertion using Kelly's forceps is deficient.

In this present study, $27 \%$ of the study subjects (24\% of Vaginal Delivery group and $30 \%$ of the LSCS group) had parity 3 or more and as much as $30 \%$ of subjects had parity, $43.5 \%$ of study subjects had only one living child ( $51 \%$ in vaginal delivery and $36 \%$ in LSCS group) one which indicates early acceptability of long term contraceptive. Similar results of earlier acceptance of intrauterine contraceptive device was found in another study of Maluchuru et al, they found that acceptance is most common among primigravida women $(31.46 \%) .{ }^{5}$ In case of multiparous it was $(12.5 \%)$ and these finding are contrary to that of the study by Grimes et al with higher acceptance in multiparous clients $(65.1 \%){ }^{6}$

In present study, it was investigated that $57.5 \%$ of the subjects had no complain at 6 week follow up (52\% in vaginal delivery group and $63 \%$ in LSCS group). At 3 months follow up 55\% subjects in Vaginal delivery group and $53 \%$ in LSCS group did not have any complain. The two groups did not differ significantly in relation to absence of complaint at 6week and 3 months follow up period. In another study by Sharma et al, in $59(61.45 \%)$ women there was no complaint regarding PPIUD results being similar to ours. ${ }^{7}$ In an another study by Shukla et al using $\mathrm{Cu}$ T $200 \mathrm{~B}$ in immediate post-partum period, they found it was only $11.3 \%$ of participants were symptom less at 6 months. ${ }^{8}$ Kittur et al has shown that $86.2 \%$ of subjects in their study were satisfied with the PPIUCD insertion. $^{9}$ Better acceptance, following standard procedure and close follow up in our study may explain the reason for the same.

Most common complication in our study was excessive vaginal bleeding, about $18 \%$ of subjects had complain of excessive vaginal bleeding at 6 weeks follow up and about $13.5 \%$. At 3 months follow up more patients in Vaginal delivery group (19\%) had complain of excessive vaginal bleeding as compared to LSCS group (8\%) and this difference was found to be statistically significant $(\mathrm{P}=0.039)$. Overall $13.5 \%$ of subjects had excessive bleeding at 3 months follow up. Welkovic et al studied post-partum bleeding and infection after post placental IUD insertion and found no difference in the incidence of excessive bleeding. ${ }^{10}$ In a review by Anita L. Nelson safety, efficacy and patient acceptability of $\mathrm{Cu} \mathrm{T} 380 \mathrm{~A}$ was studied. ${ }^{11}$
Visibility of strings is important as it assures both, the IUCD user and the health care worker about proper placement of the device, and provides ease of removal. In present study, the visibility of thread at follow up in both the groups was assessed and it was found that at 6 weeks follow up thread visibility in vaginal delivery group was significantly higher $(96 \%)$ as compared to LSCS group $(60 \%)$; $\mathrm{P}$ value $<0.001$, overall the thread visibility was not significantly different at among the two group at 3month follow up $(\mathrm{P}=0.075)$. In intracaesarean insertion, though at the time of insertion threads are not outside cervical os, involution of uterus makes them visible in most cases at the first visit; however, in a few cases threads may get curled up and not be seen at external os. This may cause apprehension to the health care worker as missing strings may indicate expulsion, malpositioning or perforation. Ultrasound was done in all cases to ensure proper placement of IUCD. Similar results were also found in study done by Single et al. ${ }^{12}$ In that study, IUCD strings were visible in $61.87 \%$ women at first visit and visibility increased to $84.62 \%$ at 12 months. In 40 (14.65\%) women strings were not visible at 12 month, despite ultrasonographic confirmation of the IUCD being in place.

Expulsion of IUCD is very important parameter which has been studied in our present study and we found that at 3 months follow up expulsion rate in vaginal delivery group was significantly higher $(10 \%)$ as compared to LSCS group (2\%) (P value=0.037). Overall the expulsion rate was $6 \%$ at 3 months. In a study by Neha Jain et al expulsion rates of the immediate PPIUCD at 4-6 wks interval were $3.5 \% .^{13}$ Lower expulsion rate in their study is explained by fact that follow up duration was just 6 weeks. But similar to our study, multi country study done in Belgium, Chile and Phillippines has showed the rate of expulsion at 1 month ranging from 4.6 to $16 \% .^{14}$ Expulsion rate of immediate PPIUCD in a study done in China by Chi et al 1994, was $25-37 \%$, while postplacental was $9.5-12.5 \%$. Expulsion of PPIUCD usually occurs in the first few months after insertion. In a multicenter investigations of Tatum et al, the expulsion rates of PPIUCD were similar at 1 and 12 months in Belgium (4\%) and Chile (7\%), while in the Philippines, expulsion increased from $19 \%$ at 1 month to $28 \%$ at 12 months follow-up. ${ }^{12,15}$ Similar to our study expulsion rate was higher among vaginal group subjects as compared to caesarean group in study conducted by Jisha bai et al. ${ }^{16}$ In a study by Kumar et al, the expulsion rate was about $3.6 \%$, in various other studies the expulsion rate of $5.6 \%$ reported among 210 women in a clinic in Hubli, Karnataka state in India. ${ }^{17}$ In a study done by Aruao et al it was $1.6 \%$ among 3000 women in a hospital in Paraguay, another study reported expulsion rate of 5.6\%, among 305 women belonging to periurban Lusaka, Zambia. ${ }^{18,19}$ In present study, the removal rate of IUCD at 6 week and 3 month follow up was $8 \%$ and $12 \%$ respectively. Chi square test shows that the two groups did not differ significantly regarding removal of IUCD in study groups. Most common cause for removal was 
excessive bleeding. IUD removal rate was $13.54 \%$ in study by Sharma et al. ${ }^{7}$ Similar to our study the common causes for removal were pelvic pain and menorrhagia. In a study by Kumar et al $3.8 \%$ of women had their PPIUCD removed within the first six weeks of insertion. ${ }^{17}$ Women most commonly reported expected side effects of IUCDs as the reasons for the removal, including bleeding and abdominal pain. These findings suggest that there is room for strengthening PPIUCD counselling services, particularly regarding normal side effects and complications that arise from method use.

In our study continuation rate for PPIUCD was good $(84.5 \%)$ at 3 months follow up. Continuation rate was significantly higher in LSCS group $(91 \%)$ as compared to vaginal delivery group $(78 \%)$; $(\mathrm{P}=0.019)$. Kittur et al has shown that $86.2 \%$ of subjects in their study continued with the PPIUCD insertion. ${ }^{10}$ Study by Jisha bai et al proved that $89 \%$ of subjects continued with immediate postpartum IUCD insertion and results are similar to our study which compised that those who had intracaesarean insertion continued more than vaginal delivery group with a statistically significant $\mathrm{p}$ value of $0.034 .{ }^{16}$ Major limitations of this study were conducted in a tertiary centre, the findings cannot necessarily be generalized to all of India since the hospital involved is a convenience sample rather than a sample representative of the country. The present study is also limited in that, long-term expulsion rates could not be determined since follow-up was only conducted at 3 months following birth. Further studies could be conducted that involved one or two-year follow-up assessments.

\section{CONCLUSION}

Post-partum insertion of IUD has the advantages of high motivation, ease of insertion and convenience for both the clients and the service provider. Immediate postpartum intrauterine device insertion showed to be a useful and safe contraceptive method. Furthermore, the use of a safe contraceptive method, provided immediately after delivery and before discharge from hospital is a farreaching reproductive health technique if we consider the high number of puerperae who do not return for contraception.

\section{ACKNOWLEDGEMENTS}

Authors would like to express the gratitude towards nursing staff, technical staff of SMS Jaipur and special thanks to all patients who participated in this study.

Funding: No funding sources Conflict of interest: None declared

Ethical approval: The study was approved by the Institutional Ethics Committee

\section{REFERENCES}

1. Post-partum IUCD reference manual. New Delhi: Family Planning Division, Ministry of Health and Family Welfare, Government of India, 2010. Available at: www.nrhmtn.gov.in.

2. Nelson A. Intrauterine contraceptives. Gynaecology and Obstetrics. Philadelphia: Lippincott Williams and Wilkins;2004;16.

3. United Nations Population information network (POPIN), UN Population division, Department of Economic and Social Affairs with support from UN Population Fund. Network Intrauterine devices. Family Health International. Winter. 1996;16(2).

4. Speroff, L, Darney, P. A Clinical Guide for Contraception. 3rd ed. Lippincott Williams Wilkins, Philadelphia; 2001.

5. Maluchuru S, Aruna V, Prabhavathi N. Post-partum: intrauterine device insertion; 2yr Experience at a tertiary care center in Guntur Medical College /Govt. General Hospital, Guntur IOSR. J Dent Med Sci. 2015;14(3):56-7.

6. Grimes D, Schulz K, Van Vliet H, Stanwood N. Immediate post-partum insertion of intrauterine devices: a Cochrane review. Hum Reprod. 2001;17(3):549-54.

7. Sharma A, Gupta V, Bansal N, Sharma U, Tandon Aet . A prospective study of immediate postpartum intra uterine device insertion in a tertiary level hospital. Int J Res Med Sci. 2015;3(1):183-7.

8. Shukla M, Qureshi S, Chandravati. Post-placental intrauterine device insertion: a five-year experience at a tertiary care centre in north India. Indian J Med Res. 2012;136:432-5.

9. Kittur S, Kabadi Y M. Enhancing contraceptive usage by post-placental intrauterine contraceptive devices (PPIUCD) insertion with evaluation of safety, efficacy, and expulsion. Int $\mathrm{J}$ Reprod Contracept Obstet Gynecol.2012;1(1):26-32.

10. Stefan Welkovic, Costa L, Faundes A, Ximenes R, Costa C. Postpartum bleeding and infection after postplacental IUD insertion. Contraception. 2011;63:155-8.

11. Anita L. Nelson. Safety, efficacy and patient acceptality of the copper T-380 A intrauterine contraceptive device. Clinical Medicine Insights. Women's Health. 2011;4:35-40

12. Singal S, Bharti R, Dewan R, Divya, Dabral A, Batra A et al . Clinical Outcome of Post-placental Copper T 380A Insertion in Women Delivering by Caesarean Section. J Clin Diagn Res. 2014;8(9):OC01-OC04.

13. Jain N, Akhtar N. A study to compare the efficacy, safety \& outcome of immediate postpartum intrauterine contraceptive device (PPIUCD) with that of delayed insertion. Int J Sci R. 2015;4(2).

14. Blanchard H, Mac Kiag C. ACCESS-FP Program. 2006. Postpartum Family planning methods and birth spacing after childbirth. Power point presentation. 
contraception:http://www.k4health.org/sites/default/f iles/postpartumabortion_English.pdf

15. Tatum HJ, Beltran RS, Ramos R, Van Kets H, Sivin I, Schmidt FH, et al. Immediate post placental insertion of GYNE-T 380 and GYNE-T 380 postpartum contraceptive devices: randomized study. Am J Obstet Gynecol. 1996;175(5):1231-5.

16. Jisha Bai C. P. A study on the complications of immediate post-partum IUCD insertion. J Evid based Medi Healthcare. 2015;2(9):1246-51.

17. Kumar S, Sethi R, Balasubramaniam S, Chaurat E, Lalchandani K, Semba R et al. Women's experience with postpartum intrauterine contraceptive device use in India. Reproduc Health. 2014;11:32.
18. Araujo VB, Ortiz L, Smith J. Postpartum IUD in Paraguay: a case series of 3000 es. Contraception. 2012, 86:173-86.

19. Blumenthal P, Shiliya N, Neukom J, Chilambwe J, Vwalika B, Prager B et al. Expulsion rates and satisfaction levels among immediate postpartum IUD users in peri-urban Lusaka, Zambia. Contraception. 2011;84:320.

Cite this article as: Lall J, Nagar O. Comparative study of post placental cut insertion following vaginal and caesarean delivery. Int J Reprod Contracept Obstet Gynecol 2017;6:901-6. 